\title{
$M$ mode and Doppler echocardiographic assessment of left ventricular diastolic function in primary antiphospholipid syndrome
}

Nicolas Coudray, Dominique de Zuttere, Olivier Blétry, Jean-Charles Piette, Bertrand

Wechsler, Pierre Godeau, Jean-Claude Pourny, Yves Lecarpentier, Denis Chemla

\begin{abstract}
Background-High titres of serum antiphospholipid antibodies are a possible pathogenic factor for cardiac lesions in patients with systemic lupus erythematosus.
\end{abstract}

Objective-To test the hypothesis of a causal link between high titres of antiphospholipid antibodies in the serum and myocardial involvement in patients without systemic lupus erythematosus.

Patients and design-18 patients with primary antiphospholipid syndrome (recurrent fetal loss, arterial and/or venous thrombosis, high titres of antiphospholipid antibodies, and no criteria for systemic lupus erythematosus) were prospectively studied by cross sectional, $M$ mode, and pulsed Doppler echocardiography, and compared with 18 healthy controls. The pulsed Doppler indices of left ventricular diastolic function included isovolumic relaxation time and four mitral outflow indices: peak velocity of early flow, peak velocity of late flow, early to late peak flow velocity ratio, and rate of deceleration of early flow. Four computerised $M$ mode indices were also measured: peak rate of left ventricular enlargement in diastole, peak rate of posterior wall thinning, peak velocity of lengthening of the posterior wall, and velocity of circumferential chamber lengthening.

Results-Compared with controls, patients with primary antiphospholipid syndrome had higher values for isovolumic relaxation time and peak velocity of late mitral outflow and lower values for early to late mitral peak outflow velocity ratio, rate of deceleration of early mitral outflow, peak rate of left ventricular enlargement in diastole, peak rate of posterior wall thinning, peak velocity of lengthening of the posterior wall and velocity of circumferential chamber lengthening.

Conclusion-This abnormal pattern reflects an impairment of myocardial relaxation and filling dynamics of the left ventricle in patients with primary antiphospholipid syndrome who were free of any clinically detectable heart disease. These data suggest that high serum titres of antiphospholipid antibodies may be associated with subclinical myocardial damage.

(Br Heart f 1995;74:531-535)
Keywords: antiphospholipid antibodies, left ventricular diastolic function, myocardial damage.

Recurrent venous and/or arterial thombosis, repeated episodes of fetal loss, and thrombocytopenia suggest the possibility of primary antiphospholipid syndrome. Diagnostic confirmation depends upon the detection of high titres of serum antiphospholipid antibodies, without evidence of systemic lupus erythematosus or malignant tumour. Cardiac manifestations have been reported in primary antiphospholipid syndrome, mainly valve lesions. ${ }^{1-3}$ Valvar, myocardial, and pericardial abnormalities are also often seen in patients with systemic lupus erythematosus. ${ }^{45}$ Several studies have found a statistical link between high titres of antiphospholipid antibodies and heart involvement, suggesting that antiphospholipid antibodies may be a key pathogenic factor for cardiac lesions in systemic lupus erythematosus. ${ }^{6-8}$ In contrast, recent studies did not find any significant correlation between antiphospholipid antibodies and valve lesions. ${ }^{9-11}$ In primary antiphospholipid syndrome antiphospholipid antibodies are present without the other features of systemic lupus erythematosus that complicate the appreciation of intrinsic cardiac involvement (hypertension, steroid or immunosuppressor treatment, renal insufficiency).

In several cardiovascular diseases diastolic function may be abnormal when systolic function remains preserved ${ }^{12}$ : this is usually regarded as an initial stage of cardiomyopathy. Early impairment of left ventricular diastolic function has been reported in systemic lupus erythematosus, especially in patients with active disease..$^{1314}$ In the present study we tested whether diastolic function was impaired in patients with primary antiphospholipid syndrome and no overt cardiac disease.

\section{Patients and methods}

\section{PATIENTS}

We studied 18 consecutive patients (two men, 16 women, mean (SD) age 36 (9)) with Asherson et al's criteria of primary antiphospholipid syndrome. ${ }^{15} \mathrm{We}$ also studied 18 age and sex matched healthy controls mean (SD) age 33 (8). All gave informed consent to the study. All patients had a physical examination, and patients with primary antiphospholipid syndrome had an electrocardiogram and a chest radiograph. We excluded those with a history of previous cardiovascular disease (hypertension, valve disease, myocardial infarction) and/or cardiac abnormality on 
physical examination. All patients were in sinus rhythm with a heart rate $<90$ beats per minute. None of the patients with primary antiphospholipid syndrome had abnormalities on the electrocardiogram or chest $x$ ray. In patients with primary antiphospholipid syndrome antiphospholipid antibody titres were measured in blood drawn within a week of the echocardiographic study. We regarded antiphospholipid antibodies as being present when we detected circulating anticoagulant and/or a high titre of anticardiolipin antibodies. We defined circulating anticoagulant as a positive diluted thromboplastin titration index $>1.3$ at $1 / 200$ final dilution and high titres of anticardiolipin antibodies were defined as a concentration of immunoglobulin $\mathrm{G}$ isotype $>20$ GPL units or a concentration of immunoglobulin $\mathrm{M}$ isotype $>10 \mathrm{MPL}$ units by enzyme-linked immunosorbent assay. ${ }^{16}$

CROSS SECTIONAL M MODE AND DOPPLER ECHOCARDIOGRAPHIC EXAMINATION

Echocardiographic examinations were performed by one experienced operator (DdZ) using an Aloka SSD 870 ultrasonoscope with 2.5 and $3.5 \mathrm{MHz}$ transducers. Measurements were made in accordance with recommendations of the American Society of Echocardiography. ${ }^{17}$ Time-motion and pulsed Doppler recordings were performed on an Aloka stripchart thermal recorder at a paper speed of $100 \mathrm{~mm} / \mathrm{s}$. Timing of the cardiac cycle was documented by simultaneous electrocardiogram recording.

Left ventricular geometry and systolic function Standard parasternal long axis and short axis views and apical views (four chamber and four chamber with aorta) were obtained. We used $M$ mode echocardiography to measure left ventricular end diastolic and end systolic dimensions and interventricular septum and left ventricular posterior wall thickness in diastole. Left ventricular fractional shortening and left ventricular mass were derived from $M$ mode measurements. Left ventricular mass was calculated according to the method recommended by Devereux et al (left ventricular mass $=0.80 \quad$ (American Society of Echocardiography - cube of left ventricular mass) $+0 \cdot 60) .{ }^{18}$ Left ventricular segmental wall motion was assessed systematically using cross sectional echocardiography. Wall motion abnormalities were assessed by visually evaluating wall motion and endocardial thickening of the different left ventricular wall segments, as recommended by the American Society of Echocardiography. ${ }^{19}$

\section{Assessment of left ventricular filling}

Pulsed Doppler recordings were obtained in expiration, with the sample volume located between the tips of mitral leaflets. ${ }^{20}$ We measured the peak velocity of early mitral outflow $(\mathrm{cm} / \mathrm{s})$, the peak velocity of late mitral outflow $(\mathrm{cm} / \mathrm{s})$, early to late peak outflow velocity ratio, and the rate of deceleration of velocity in early diastole $\left(\mathrm{m} / \mathrm{s}^{2}\right)$. All values were averaged out over three consecutive cardiac cycles.

\section{ISOVOLUMIC RELAXATION TIME}

The isovolumic relaxation time, defined as the interval between aortic valve closure and mitral opening, was measured from beat to beat recordings of left ventricular filling and ejection flows by pulsed Doppler. The sample volume was located at the left ventricular outflow tract close to the anterior mitral leaflet (to allow the recording of both aortic closure and mitral opening sounds). Isovolumic relaxation time was averaged out over three consecutive cycles.

\section{Endocardium, Pericardium}

We looked for valve thickening and/or pericardial effusion in each patient.

\section{COMPUTERISED DIGITISATION OF M MODE LEFT} VENTRICULAR RECORDINGS

The lengthening capabilities of the myocardium during early diastole were precisely quantified by computer-assisted digitisation of $M$ mode echocardiographic recordings. ${ }^{21}$ Recordings from the endocardium and epicardium of the posterior wall and recordings from the interventricular septum were manually traced on a digitising tablet connected to a microcomputer (Hewlett Packard 1000, self-devised software. data point recording at $10 \mathrm{~ms}$ intervals). The Penn convention ${ }^{18}$ was applied for left ventricular wall tracings. The indices measured were the peak rate of left ventricular enlargement in diastole $(\mathrm{cm} / \mathrm{s})$, the peak rate of posterior wall thinning $(\mathrm{cm} / \mathrm{s})$, the velocity of circumferential chamber lengthening $\left(\mathrm{s}^{-1}\right)$, and the peak velocity of lengthening of the posterior wall $(\mathrm{cm} / \mathrm{s}) .{ }^{21}$ The accuracy of the digitisation procedure was improved by automatically averaging each trace at least three times, and each measurement over three consecutive cardiac cycles, as recommended..$^{22}$

\section{REPRODUCIBILITY OF MEASUREMENTS}

To test the interobserver variability for echocardiographic measurements, we randomly selected $15 \mathrm{M}$ mode recordings of the left ventricle, 15 pulsed Doppler recordings used for isovolumic relaxation time determination, and 15 pulsed Doppler recordings of mitral outflow. Indices of left ventricular diastolic function were measured independently by two observers unaware of patients' diagnoses. Interobserver variability was calculated as the absolute value of the difference between the two measurements divided by the average of two measurements multiplied by $100 \%$. Mean values of interobserver variability were $2 \cdot 1 \%$ (SD $0 \cdot 4 \%$ ) for computerised $M$ mode measurements, and $6.2 \%$ (SD $5 \cdot 3 \%$ ) for mitral outflow indices. Percentage of interobserver variability for isovolumic relaxation time measurements was $4 \cdot 3 \%$ (SD $3 \cdot 6 \%$ ).

\section{STATISTICAL ANALYSIS}

Data are mean (SD) values. Groups were compared by Student's unpaired $t$ test. Differences between groups of $p<0.05$ were regarded as significant. 
Table 1 Clinical and echocardiographic indices (mean (SD)) in patients with primary antiphospholipid syndrome (PAPS) and controls

\begin{tabular}{lcc}
\hline Index & $\begin{array}{c}\text { Controls } \\
(n=18)\end{array}$ & $\begin{array}{c}P A P S \\
(n=18)\end{array}$ \\
\hline Age (y) & $33(8)$ & $36(9)$ \\
Heart rate (beat/min) & $66(9)$ & $71(6)$ \\
Systolic BP (mm Hg) & $121(9)$ & $128(14)$ \\
Diastolic BP (mm Hg) & $68(8)$ & $73(12)$ \\
LV mass index $\left(\mathrm{g} / \mathrm{m}^{2}\right)$ & $90(19)$ & $87(17)$ \\
LV EDD $(\mathrm{mm})$ & $48(4)$ & $49(4)$ \\
LV ESD (mm) & $29(3)$ & $31(4)$ \\
FS (\%) & $37(5)$ & $37(5)$ \\
\hline
\end{tabular}

BP, blood pressure; EDD, end diastolic diameter; ESD, end systolic diameter; FS, fractional shortening; LV, left ventricular.

Table 2 Pulsed Doppler and computerised $M$ mode indices (mean (SD)) in patients with primary antiphospholipid syndrome and in controls

\begin{tabular}{|c|c|c|}
\hline & $\begin{array}{l}\text { Control group } \\
(n=18)\end{array}$ & $\begin{array}{l}\text { PAPS } \\
\text { group }\end{array}$ \\
\hline $\begin{array}{l}\text { E wave }(\mathrm{cm} / \mathrm{s}) \\
\text { A wave }(\mathrm{cm} / \mathrm{s}) \\
\text { E/A } \\
\text { IVRT }(\mathrm{ms}) \\
\text { EF slope }\left(\mathrm{m} / \mathrm{s}^{2}\right) \\
\text { D+ }(\mathrm{cm} / \mathrm{s}) \\
\text { PWT }(\mathrm{cm} / \mathrm{s}) \\
\text { PVL }(\mathrm{cm} / \mathrm{s}) \\
\operatorname{VCL}\left(\mathrm{s}^{-1}\right)\end{array}$ & $\begin{array}{l}74(12) \\
45(6) \\
1 \cdot 68(0.37) \\
85(15) \\
5 \cdot 8(1 \cdot 5) \\
15 \cdot 9(3 \cdot 3) \\
10 \cdot 6(3 \cdot 1) \\
12 \cdot 7(2 \cdot 8) \\
4 \cdot 6(0.9)\end{array}$ & $\begin{array}{l}69(14)(\mathrm{n}=18) \\
54(16)(\mathrm{n}=18)^{\star} \\
1 \cdot 35(0 \cdot 45)(\mathrm{n}=18)^{\star} \\
95(15)(\mathrm{n}=18)^{\star} \\
4 \cdot 8(1 \cdot 3)(\mathrm{n}=18)^{\star} \\
11 \cdot 5(3 \cdot 5)(\mathrm{n}=13) \dagger \\
8 \cdot 4(2 \cdot 8)(\mathrm{n}=13)^{\star} \\
9 \cdot 8(3 \cdot 3)(\mathrm{n}=13)^{\star} \\
3 \cdot 4(1 \cdot 2)(\mathrm{n}=13) \dagger\end{array}$ \\
\hline
\end{tabular}

$\mathrm{E}$, peak early diastolic filling velocity; $\mathrm{A}$, peak filling velocity at atrial contraction; IVRT, isovolumic relaxation time; EF slope rate of deceleration of velocity in early diastole; $\mathrm{D}+$, peak rate of left ventricular enlargement in diastole; PWT, posterior wall thinning rate; PVL, peak velocity of lengthening of the posterior wall; VCL, velocity of circumferential chamber lengthening. $\star P<0.05$ and $+P<0.01 v$ controls.

\section{Results}

There were eight cases of mild valve disease (three mitral and two aortic regurgitation) and five small pericardial effusions in the primary antiphospholipid syndrome group. There were no differences between the two groups in heart rate, systolic or diastolic arterial blood pressure, left ventricular end diastolic and end systolic dimensions, or left ventricular mass and fractional shortening (table 1). This meant that diastolic indices could be validly compared.

\section{PULSED DOPPLER STUDY}

Compared with controls, patients with primary antiphospholipid syndrome had a prolonged isovolumic relaxation time $(P<0.05)$, an increased peak velocity of late mitral outflow $(P<0.05)$, and decreased values for the rate of deceleration of velocity in early diastole $(P<0.05)$ and for the early to late peak outflow velocity ratio $(P<0.05)$ (table 2 and figs 1-5).

Figure 1 Peak early filling velolcities $(E)$ of the control group, and of patients with primary antiphospholipid syndrome (PAPS). Shaded area indicates the normal range with $95 \%$ confidence intervals.

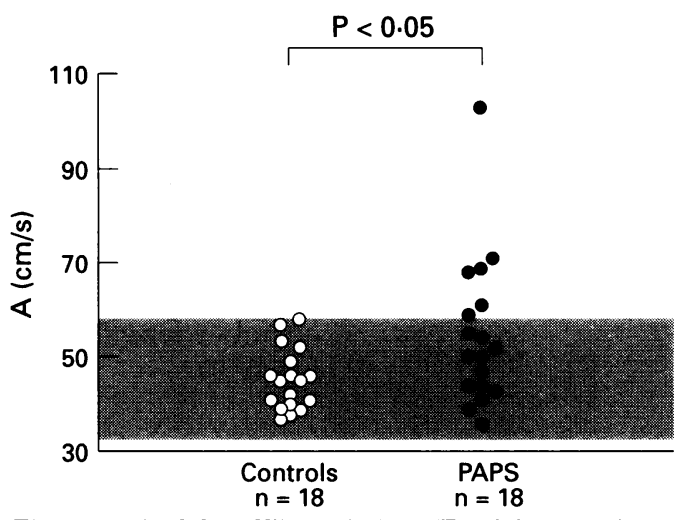

Figure 2 Peak late filling velocities (E) of the control group, and of patients with primary antiphospholipid syndrome (PAPS). Shaded area as in fig 1.

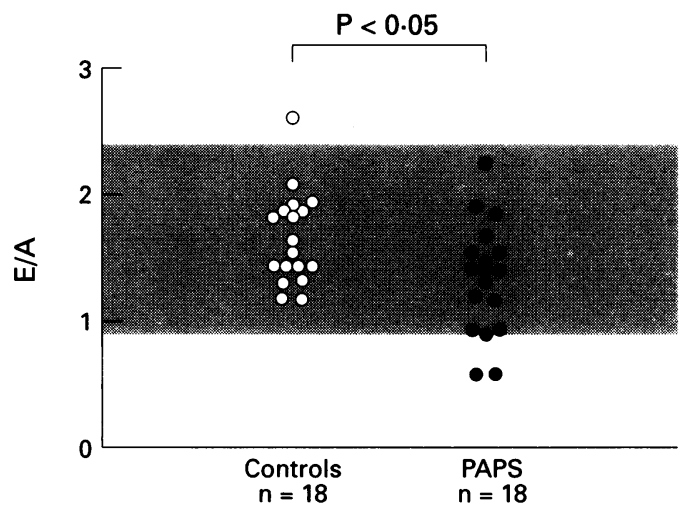

Figure $3 E / A$ ratios of the control group and of patients with primary antiphospholipid syndrome (PAPS). Shaded area as in fig 1 .

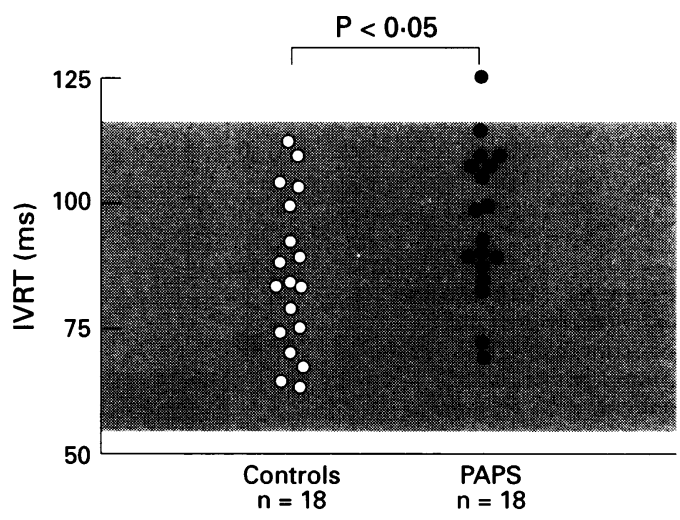

Figure 4 Isovolumic relaxation times (IVRT) of the control group and of patients with primary antiphospholipid syndrome (PAPS). Shaded area as in fig 1 .

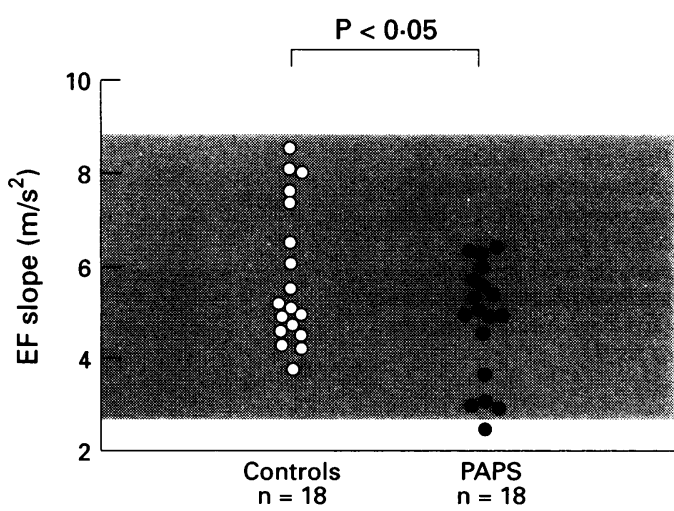

Figure 5 Rates of deceleration of velocity in early diastole (EF slope) of the control group and of patients with primary antiphospholipid syndrome (PAPS). Shaded area as in fig 1. 
Figure 6 Peak rates of left ventricular enlargement in diastole $(D+)$ of the control group and of patients with primary antiphospholipid syndrome (PAPS). Shaded area as in fig 1 .

Figure 7 Posterior wall thinning rates (PWT) of the control group and of patients with primary antiphospholipid syndrome (PAPS). Shaded area as in figure 1.
Figure 8 Peak velocities posterior wall (PVL) of the control group and of patients with primary antiphospholipid syndrome (PAPS). Shaded area as in fig 1 . of lengthening of the

COMPUTERISED M MODE STUDY

The patients with primary antiphospholipid syndrome had lower values than the controls for the four measured indices: peak rate of left ventricular enlargement in diastole $(P<0.01)$, posterior wall thinning rate $(p<0.05)$, peak velocity of lengthening of the posterior wall $(P<0.05)$ and velocity of circumferential chamber lengthening $(P<0.01)$ (table 2 and figs 6-9).
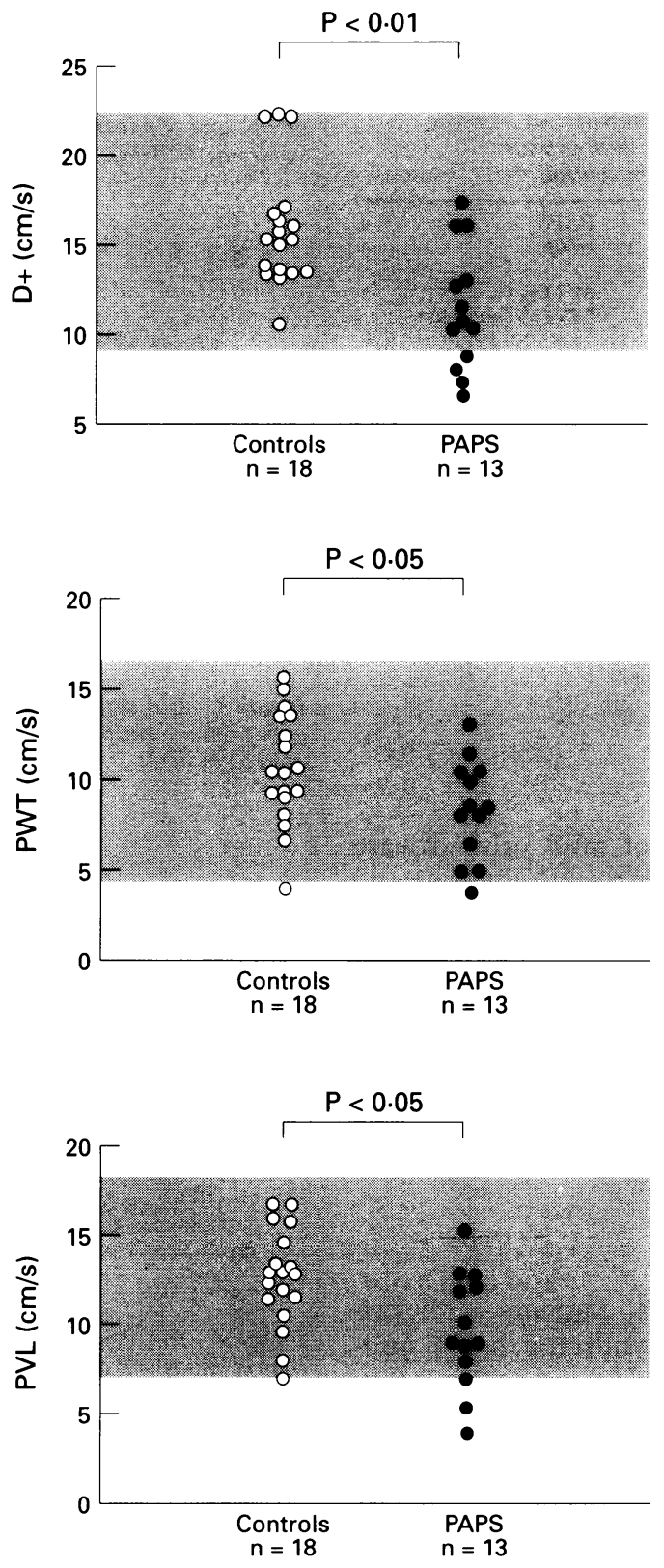

Figure 9 Velocities of circumferential chamber lengthening ( $V C L)$ of the control group and of patients with primary antiphospholipid syndrome (PAPS). Shaded area as in fig 1 .

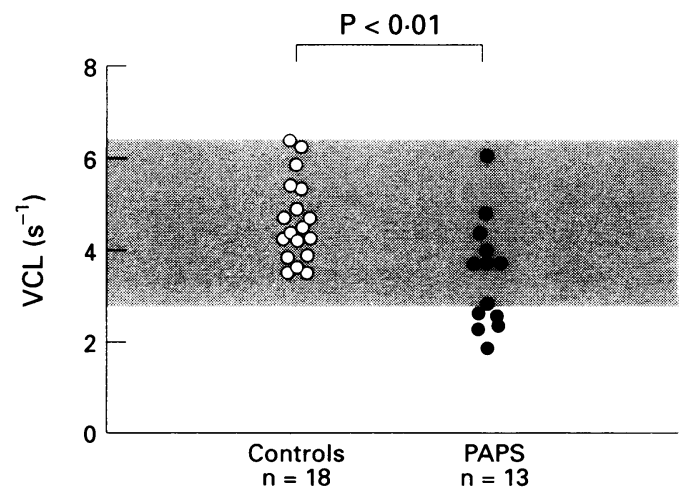

\section{Discussion}

This prospective, non-invasive study showed an abnormal Doppler and computerised $M$ mode pattern of left ventricular diastolic function in a group of 18 patients with primary antiphospholipid syndrome none of whom had any clinically detectable manifestation of cardiac disease.

We found a prolonged isovolumic relaxation time, a disturbed left ventricular early filling pattern, and a decreased myocardial lengthening rate in the primary antiphospholipid syndrome group. This may indicate impaired myocardial relaxation and/or filling dynamics of the left ventricle ${ }^{23}$ in these patients whose systolic performance indices were normal. Similarly, diastolic dysfunction with preserved systolic function has been reported at the early stages of cardiovascular diseases including hypertension and coronary artery disease. ${ }^{12}$

All except one of our patients were less than 45 years old, all of them had normal heart rate, blood pressure, and left ventricular systolic function and mass index; none of them had any previous history of coronary heart disease. Thus the main physiopathological conditions known to alter left ventricular relaxation or filling dynamics were excluded, so that the diastolic function abnormalities can be regarded as being directly related to the illness itself.

We found only two reports of myocardial involvement in patients with primary antiphospholipid syndrome. ${ }^{1524}$ Asherson et al found five cases of myocardial infarction in a series of 70 patients with primary antiphospholipid syndrome. ${ }^{15}$ Murphy and Leach reported the case of a 33 year old man with primary antiphospholipid syndrome who died of cardiac failure. Histological examination of the myocardium showed extensive platelet thrombi within small intracardiac arteries with areas of microinfarction. Antiphospholipid antibodies may disrupt the normal coagulation cascade by interfering with phospholipid surface interactions among endothelial cells, platelets, and circulating proteins.

Myocardial involvement has been more extensively studied in patients with systemic lupus erythematosus. Left ventricular diastolic dysfunction has been recently reported in lupus, ${ }^{13} 1425$ but without any reference to a possible link with high titres of antiphopholipid antibodies. On the other hand, segmental or global left ventricular hypokinesis has been observed in lupus patients, and has been correlated to the presence of high titres of antiphospholipid antibodies. ${ }^{67}$ Histological evidence of inflammation, immune deposits in the wall of blood vessels of myocardium, ${ }^{26}$ and widespread intramyocardial arteriolar thrombosis with surrounding myocardial necrosis ${ }^{125}$ have been reported. A link between the presence of antiphospholipid antibodies and microvascular lesions resulting in myocardial ischaemia has thus been suspected in patients with lupus. ${ }^{127}$ Myocardial ischaemia mediated by antiphospholipid antibody may slow isometric relaxation and impair left ventricular 
filling, in the same manner as reported in patients with coronary heart disease. ${ }^{12}$

We found an abnormal filling pattern in patients affected by primary antiphospholipid syndrome without any previous history of myocardial infarction or coronary artery disease. This is further evidence of a causal link between high serum titres of antiphospholipid antibodies and cardiac involvement in primary antiphospholipid syndrome and, by extension, in systemic lupus erythematosus.

\section{LIMITATIONS}

Pulsed Doppler echocardiography is a simple, reproducible method for studying the relaxation period and the dynamics of filling of the left ventricle considered as a pump, but has several limitations, in particular ignorance of left atrial pressure level. ${ }^{20}$ Left ventricular computerised $\mathrm{M}$ mode recordings describe diastolic properties of the left ventricle considered as muscle, ${ }^{20}$ but for one cross sectional diameter only. However, both methods showed diastolic abnormalities in patients with primary antiphospholipid syndrome and this strengthens the relevance of our results.

\section{CONCLUSION}

We report previously undescribed abnormalities of left ventricular relaxation and early filling dynamics in a group of patients with primary antiphospholipid syndrome and no clinical symptoms of cardiac disease. Further studies are needed to determine the relation between the impaired diastolic function associated with high titres of serum antiphospholipid antibodies and the later development of contractile state disorders. It also remains to be established whether antiplatelet or anticoagulant drug treatment can prevent diastolic dysfunction in patients with primary antiphospholipid syndrome.

This study was supported by grants from INSERM/CNAMTS and Fondation pour la Recherche Médicale and presented a the IVth Conference on Non-invasive Cardiology, Limassol Cyprus, October 1993 de Zuttere D, Coudray N, Blétry O Piette JC, Wechsler B, Godeau P, Glaser E, Pourny JC, Lecarpentier Y, Chemla D. Left ventricuar diastolic dysfunction in primary antiphospholipid syndrome (abstr). Am $\mathcal{f}$ Cardiac Imaging 1994;8:324.

1 Kaplan SD, Chartash EK, Pizzarello RA, Furie AF. Cardiac manifestations of the antiphospholipid syndrome. Am Heart f 1992;124:1331-8.

2 Brenner B, Blumenfeld Z, Markiewicz W, Reisner SA. Cardiac involvement in patients with primary antiphospholipid syndrome. F Am Coll Cardiol 1991;18:931-6.

3 Galve E, Ordi J, Barquinero J, Evangelista A, Vilardell M, Soler-Soler J. Valvular heart disease in the primary antiphospholipid syndrome. Ann Intern Med 1992; 116:293-8.

4 Chia BI, Mah EP, Feng PH. Cardiovascular abnormalities in systemic lupus erythematosus. $\mathcal{f}$ Clin Ultrasound 1981;9:237-43

5 Galve E, Candell-Riera J, Pigrau C, Permayer-Miralda G,
Del-Castillo HG, Soler-Soler J. Prevalance, morphologic types, and evolution of cardiac valvular disease in systemic lupus erythematosus. $N$ Engl f Med 1988;319: 817-23.

6 Leung WH, Wong KL, Lau CP, Wong CK, Liu HW. Association between antiphospholipid antibodies and cardiac abnormalities in patients with systemic lupus erythematosus. Am f Med 1990;89:41 1-9.

7 Nihoyannopoulos P, Gomez PM, Joshi J, Loizou S, Walport MJ, Oakley CM. Cardiac abnormalities in systemic lupus erythematosus, association with raised antitemic lupus erythematosus, association with raised

8 Khamashta MA, Cervera R, Asherson RA, Font J, Gil A, Coltart DJ, et al. Association of antibodies against phospholipids with heart valve disease in systemic lupus erythematosus. Lancet 1990;335:1541-4.

9 Roldan CA, Shively BK, Lau CC, Gurule FT, Smith EA, Crawford $M H$. Systemic lupus erythematosus valve disease by transesophageal echocardiography and the role of antiphospholipid antibodies. $\mathcal{F}$ Am Coll Cardiol 1992; 20:1127-34.

$10 \mathrm{Li}$ EK, Crozier IG, Milne MJ, Nicholls MG, Cohen MG. Lack of association between anticardiolipin antibodies and heart valve disease in Chinese patients with systemic lupus erythematosus. Lancet 1990;336:504-5.

11 Gleason CB, Stoddard MF, Wagner SG, Longaker RA, Pierangeli S, Harris EN. A comparison of cardiac valvular involvement in the primary antiphospholipid syndrome versus anticardiolipin-negative systemic lupus erythematosus. Am Heart f 1993;125:1 123-9.

12 Grossman $W$. Diastolic dysfunction in congestive heart failure. N Engl f Med 1991;325:1557-64.

13 Crozier IG, Li E, Milne MJ, Nicholls MG. Cardiac involvement in systemic lupus erythematosus detected by echocardiography. Am $\mathcal{F}$ Cardiol 1990;65:1145-8.

14 Sasson Z, Rasooly Y, Chow CW, Marshall S, Urowitz MB. Impairment of left ventricular diastolic function in systemic lupus erythematosus. Am $\mathcal{F}$ Cardiol 1992;69: 1629-34.

15 Asherson RA, Khamashta MA, Ordi-Ros J, Derksen RHWM, Marchin SJ, Barquinero J, et al. The "primary antiphospholipid syndrome": Major clinical and serological features. Medicine (Baltimore) 1989;68:366-74.

16 Harris EN, Gharavi AE, Boey ML, Patel BM, MackworthYoung CG, Loizou S, et al. Anticardiolipin antibodies: detection by radioimmunoassay and association with thrombosis in systemic lupus erythematosus. Lancet 1983;i:1211-4.

17 Sahn DJ, DeMaria A, Kislo J, Weyman A. Recommendations regarding quantitation in $M$-mode echocardiography: results of a survey of echocardiographic measurements. Circulation 1978;58:1072-7.

18 Devereux RB, Alonso DR, Lutas EM, Gottlieb GJ, Campo $\mathrm{E}$, Sachs I, et al. Echocardiographic assessment of left ventricular hypertrophy: comparison to necropsy findings. $A m \mathcal{F}$ Cardiol 1986;57:450-8.

19 Schiller NB, Shah PM, Crawford M, DeMaria A, Devereux R, Feigenbaum $\mathrm{H}$, et al. Recommendations for quantitation of the left ventricle by two-dimensional quantitation of the left ventricle by two-dim

20 de Zuttere D, Touche T, Saumon G, Nitenberg A, Prasquier R. Doppler echocardiographic measurement of mitral flow volume: validation of a new method in adult mitral flow volume: validation of a new me

21 St John Sutton MG, Reichek N, Kastor JA, Giuliani ER. Computerized $M$-mode echocardiographic analysis of left ventricular dysfunction in cardiac amyloid. Circulation 1982;66:790-9.

22 Pollick C, Fitzgerald PJ, Popp RL. Variability of digitized echocardiography: size, source and means of reduction. Am $\mathcal{f}$ Cardiol 1983;51:576-82.

23 Nishimura RA, Housmans PR, Hatle LK, Tajik AJ. Assessment of diastolic function of the heart: background Assessment of diastolic function of the heart: background and current applications of Doppler echocardiography. Part I. Physiologic and phys
Clin Proc 1989;64:71-81.

24 Murphy JL, Leach IH. Findings at necropsy in the heart of a patient with anticardiolipin syndrome. $\mathrm{Br}$ Heart $\mathcal{f}$ 1989;62:61-4.

25 Leung WH, Wong $\mathrm{KL}$, Lau CP, Wong CK, Cheng $\mathrm{CH}$, Tai YT. Doppler echocardiographic evaluation of left ventricular diastolic function in patients with systemic lupus erythematosus. Am Heart $\mathcal{f}$ 1990;120:82-7.

26 Bidani AK, Roberts JL, Schwartz MM, Lewis EJ. Immunopathology of cardiac lesions in fatal systemic lupus erythematosus. $\mathrm{Am} 7 \mathrm{Med}$ 1980;69:849-58.

27 Brown JH, Doherty CC, Allen DC, Morton P. Fatal cardiac failure due to myocardial microthrombi in systemic lupus erythematosus. B Med $\mathcal{f}$ 1988;296:1505. 